\title{
Corrosion of carbon steel caustic header in the presence of chloride ions
}

\author{
Anwar UI-Hamid *, Hani M Tawancy \\ Center for Engineering Research. Research institute. King Fahd University of Petroleum and Minerals. P.O. Box 1073. Dhahran 31261. Saudi Arabia
}

\section{ARTICLE INFO}

Article history:

Received 6 April 2008

Received in revised form 18 June 2008

Accepted 6 July 2008

Available online $\mathrm{xxxx}$

\section{Keywords:}

Caustic header

Corrosion

Petrochemical

Failure

Microstructure

\begin{abstract}
A B S T R ACT
Caustic soda produced in caustic cells at a petrochemical plant was loaded into a crude tank by means of a caustic header line made of plain carbon steel. After a fraction of expected service life, the header was severely corroded. Scanning electron microscopy (SEM) coupled with energy dispersive X-ray spectroscopy (EDS) and X-ray diffraction (XRD) was used to identify the material and the corrosion product. Metallurgical evaluation suggested that the mode of failure was localized attack by chlorine and/or hydrochloric acid at pipe connections (flanges) where concentrated solutions could accumulate. Most evidence pointed out that the failure resulted from corrosion attack due to condensation of hydrochloric acid. Misalignment of the pipe at the flange led to cold work which is also thought to accelerate the corrosion rate. It was recommended to consider a better pipe alignment practice as well as the addition of an inhibitor as a short-term solution. Since the piping system was used close to the critical operating conditions. it was recommended as a long-term solution to replace the caustic header material by one of the higher grades Ni-Cr-Mo alloys.
\end{abstract}

(C) 2008 Elsevier Ltd. All rights reserved.

\section{Background}

A petrochemical plant produced $\sim 500, \mathrm{OOO}$ tons of caustic soda (sodium hydroxide, $\mathrm{NaOH}$ ) annually. The caustic soda was produced by feeding both salt $(\mathrm{NaCl})$ and water into caustic cells, thereby resulting in the following basic reaction:

$$
2 \mathrm{NaCl}(\mathrm{aq})+2 \mathrm{H}_{2} \mathrm{O} \rightarrow \mathrm{Cl}_{2} \text { (gas) }+\mathrm{H}_{2} \text { (gas) }+2 \mathrm{NaOH}(\mathrm{aq})
$$

Some of the water fed into the caustic cell was consumed in the above reaction and the remainder left the cell as saturated vapor along with chlorine and hydrogen gases. In this process, it is necessary to prevent reaction of the $\mathrm{NaOH}$ with the chlorine which was accomplished by means of an ion selective membrane or porous membrane. Caustic soda was transferred into a crude tank using caustic header line consisting of 10 in. and 16 in. diameter pipes as schematically illustrated in Fig. 1.

After a short period of usage, severe corrosion occurred particularly concentrated at two locations of the 16 in. header. At the top section, corrosion initiated in the flange and extended about $1.5 \mathrm{~m}$ into the pipe as illustrated in Fig. 1 . However, at the bottom section, corrosion occurred in the flange only. Four sections of the failed pipe/flange were evaluated as described below:

(a) One section of the 16 in. diameter flanged pipe removed from the top section.

(b) One section of the 16 in. diameter pipe removed from the top section.

- Corresponding author.

E-mail address:anwar@kfupm.edu.sa (A. UI-Hamid).

1350-6307 \{\$ - see front matter ๔ 2008 Elsevier Ltd. All rights reserved.

doi: 10.1 016/j.engfailanaI.2008.07.003

Please cite this article in press as: UI-Hamid A, Tawancy HM, Corrosion of carbon steel caustic header in the presence of chloride ions, Eng Fail Anal (2008), doi:10.1016/j.engfailanaI.2008.07.003 


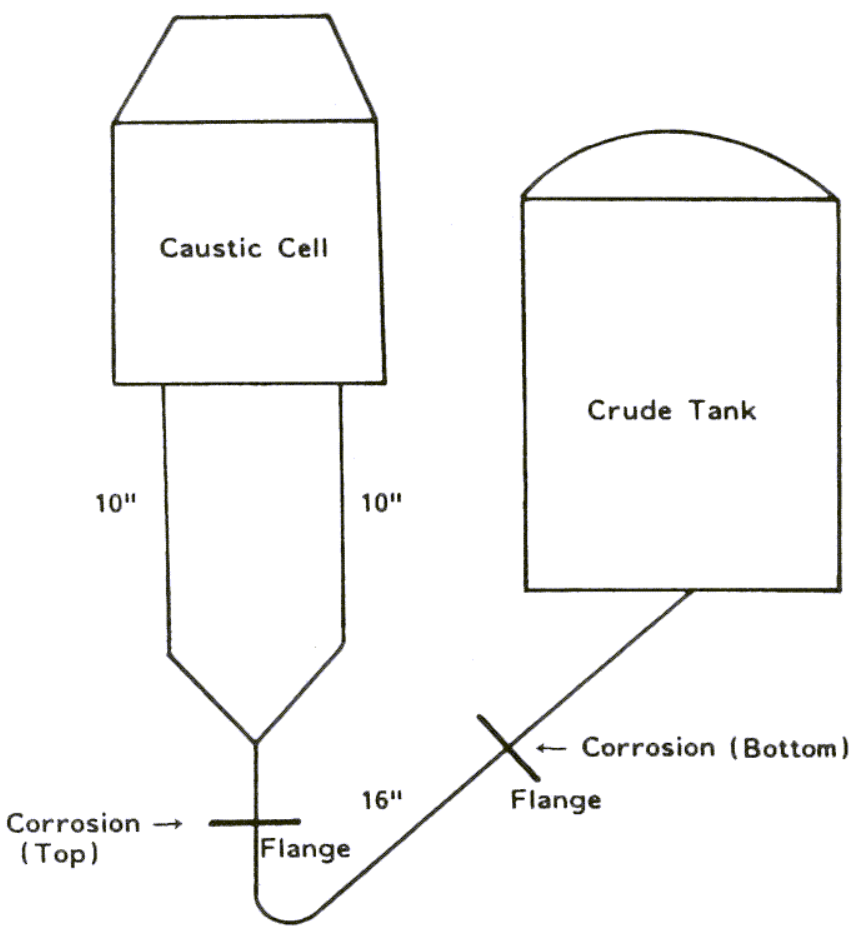

Fig. 1. Schematic illustration of the caustic cell and the locations of corrosion attack.

(c) One section of the 10 in. diameter flanged pipe.

(d) One section of the $10 \mathrm{in}$. diameter pipe.

Also, corrosion deposit removed from the $16 \mathrm{in}$. diameter flanged pipe at the top section was characterized. Table 1 summarizes the design specifications of the caustic header. It was the objective of this investigation to metallurgically evaluate the corroded caustic header to identify the mode of failure, determine the cause of failure, and provide proper recommendations to combat the problem.

\section{Experimental procedure}

Selected specimens were prepared from the as-received sections of the header for metallurgical evaluation. Specimens were examined in the as-received, polished and etched conditions. All specimens were etched in nital solution (2.5\% nitric acid). Microstructural features were characterized using scanning electron microscopy (SEM) in the emissive mode. Chemical analysis of the header and flange materials as well as the corrosion deposit was conducted by energy dispersive X-ray spectroscopy (EDS) in the SEM. Phase analysis of the corrosion deposit was carried out by X-ray diffraction (XRD).

\section{Results and discussion}

\subsection{Visual inspection}

Visual inspection revealed that the corrosion attack was localized in nature. The 16 in. diameter caustic header lost its structural integrity as a result of an attack by what appeared to be a highly corrosive environment. Metal wastage occurred

Table 1

Design specifications of the caustic header

Size (in.)

Pipe material

Operating temperature $\left({ }^{\circ} \mathrm{C}\right)$

Design pressure (kPa)

Service

Flow $\left(\mathrm{m}^{3} / \mathrm{d}\right)$

Velocity ( $\mathrm{ft} / \mathrm{s})$

Flange material of 10 in. pipe
16

API SLB STD

110

1035

11-13\% caustic with $12-15 \% \mathrm{NaCl}, 0.4-0.8 \%$ Sodium sulfate and 5-50 ppm sodium hypochlorite 2542

0.74

590 MFF 10150 B16A105N STD 42238 Italy 
to the extent that the header material was perforated. The nature of the attack at the top section was somewhat different from that at the bottom section. Massive corrosion deposits were formed at the top section, while evidence for the presence of corrosion products was not found at the bottom section. Restriction of the corrosion attack to pipe connection at the flanges suggests either galvanic corrosion and/or caustic embrittlement [1].

\subsection{Material verification}

Energy dispersive X-ray spectra derived from the $16 \mathrm{in.} \mathrm{diameter} \mathrm{pipe} \mathrm{and} \mathrm{its} \mathrm{flange} \mathrm{using} \mathrm{an} \mathrm{EDS} \mathrm{detector} \mathrm{in} \mathrm{a} \mathrm{secondary}$ electron microscope (SEM) showed primarily Fe with small amounts of Mn. The spectra are indistinguishable suggesting similarity in the chemical compositions of the pipe and flange material. It is to be noted, however, that elements which can be detected by an X-ray spectrometer were limited to $\mathrm{Na}$ and heavier elements. Therefore, no $\mathrm{C}$ peaks were detected. However, the amount of pearlite in the microstructure of carbon steels is directly proportional to the C content. Secondary electron SEM images illustrating characteristic microstructural features of the pipe and flange materials are illustrated in Fig. 2. It is observed that the amount of pearlite in the pipe material approaches that of the flange material suggesting similar $\mathrm{C}$ contents. To summarize, both spectral and microstructural data derived from the material appeared to be consistent with the grades of carbon steels stated in the design specifications.

Based upon the above results, it could be concluded that a galvanic effect was not a contributory factor in the corrosion attack. Also, the materials of the $10 \mathrm{in}$. diameter pipe and its flange were found to have a microstructure and chemical composition similar to that observed for 16 in. diameter pipe.

\subsection{Analysis of the corrosion deposit}

Corrosion deposit removed from the top section of the $16 \mathrm{in}$. diameter header was analyzed by X-ray diffraction. The deposit consisted of a mixture of iron oxides and chlorides as summarized in Fig. 3. Characteristic morphology and chemical composition of the deposit are shown in the SEM images and EDS spectra of Fig. 4 where strong $\mathrm{Cl}$ peaks can be observed. Analysis of several samples of the deposit suggested that chlorides were mostly concentrated in the outer sections of the deposit.

Above results indicate that the top section of the header was exposed to chlorine. The material of the header initially developed a surface oxide scale which was subsequently attacked by chlorine. As a result, the surface oxide was converted into a porous non-protective scale which contributed to an acceleration of the oxidation attack. By analogy to caustic embrittlement [1], there is also a possibility that accumulation of concentrated solutions at the pipe connection (flange) led to the generation of chlorine. This may explain why the corrosion attack started at the flange. A further evidence for chlorine attack of the $16 \mathrm{in}$. header at the top section was provided by analysis of surface scale as described in Section 3.5 .

\subsection{Microstructural characterization}

Typical microstructural features of the $16 \mathrm{in}$. diameter pipe and flange materials are shown in the secondary electron SEM images of Fig. 5. Elongated pearlite, particularly near the inner surface of the pipe, indicated a cold-worked layer possibly resulting from improper installation of the header. Cold working is known to accelerate the corrosion rate [1]. In contrast, the flange was free of cold working. It is possible that the cold working played a considerable role in extending the corrosion attack from the flange into the pipe as observed. Similar results were obtained for the 10 in. diameter pipe and flange.

a

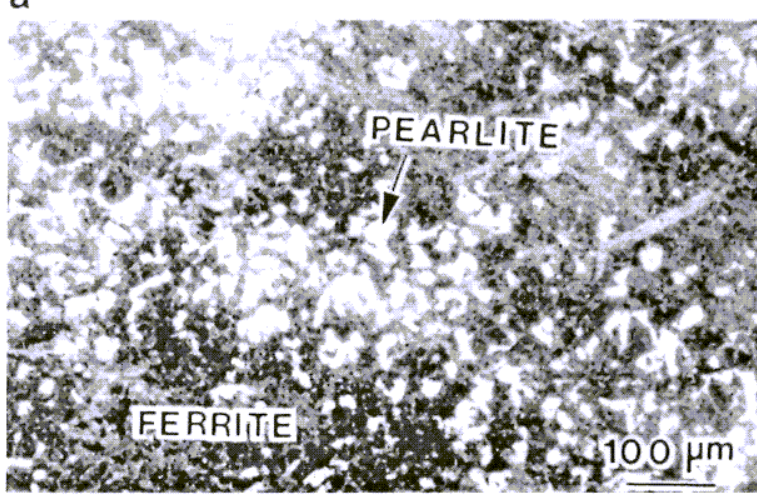

b

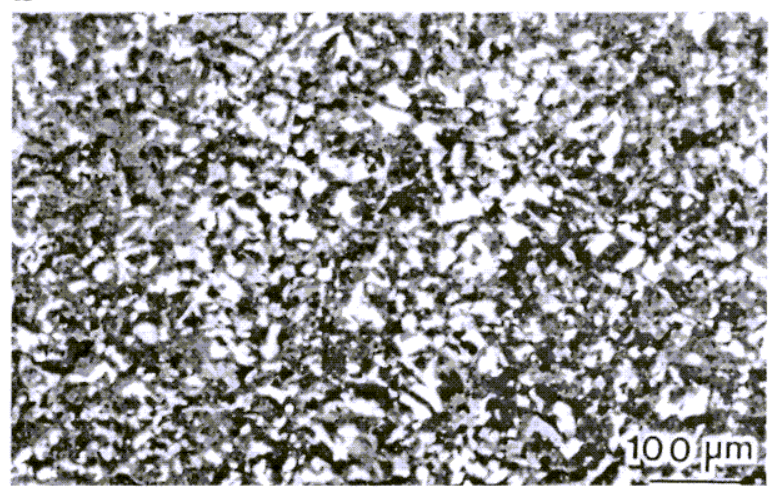

Fig. 2. Secondary electron SEM images illustrating gross microstructural features of the 16 in. header parallel to the surface: (a) pipe and (b) flange. 

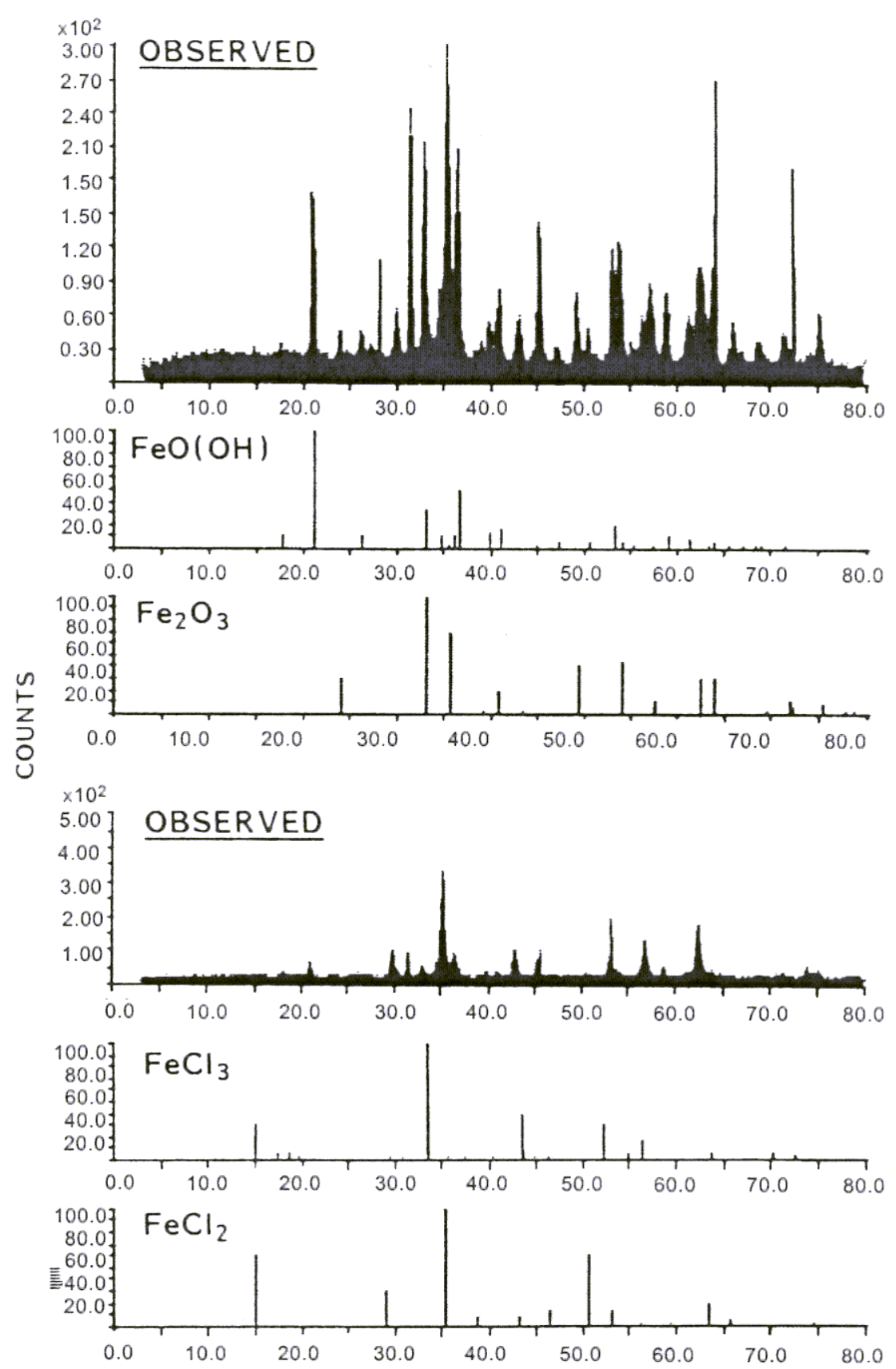

Fig. 3. X-ray diffraction patterns derived from the corrosion deposit removed from the top section of the 16 in. header.

\subsection{Analysis of surface scale}

Analysis of the surface scale formed at the top section of the 16 in. header revealed the presence of iron chloride as illustrated in the example of Fig. 6. However, there was no evidence for the presence of chlorine-rich phases in the surface scale of the flange. This could be attributed to the severity of the attack initiated at the flange that eventually led to spallation of chlorine-rich phases.

Pits were observed at the internal surface of the flange of the $16 \mathrm{in}$. header, as shown in Fig. 7. Predominantly, the pits consisted of iron-rich oxides. However, it is possible, that these pits contained chlorine-rich phases which were washed away. When observed along the transverse direction, these pits appeared to be associated with intergranular corrosion attack as illustrated in Fig. 8. Cracking due to intergranular corrosion in carbon steels is known to occur in components such as headers, pipe connections and tube ends and ligaments at areas where concentrated solution is accumulated and stresses are 

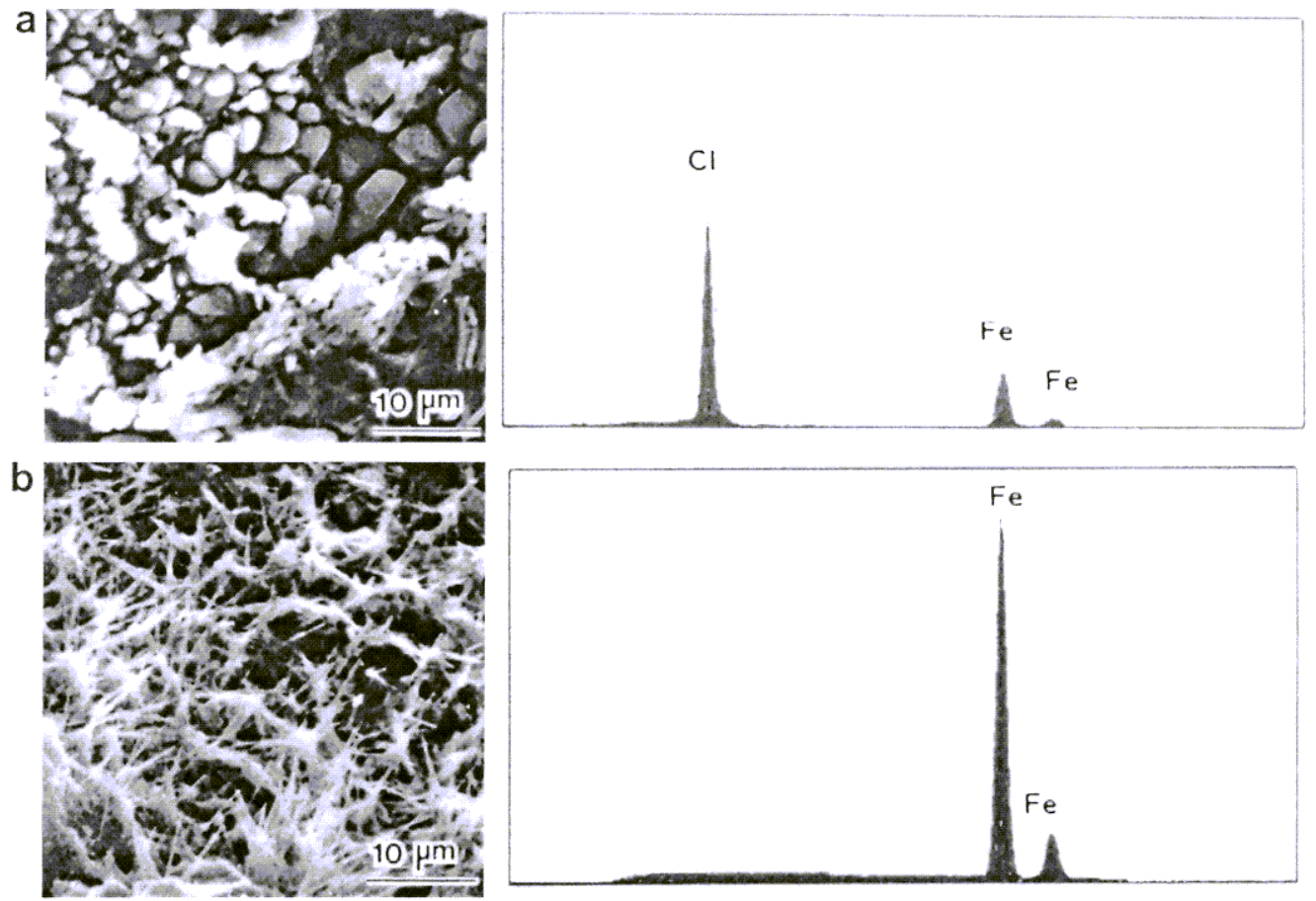

Fig. 4. Analysis of the morphology and composition of corrosion deposit removed from the top section of the 16 in. header: (a) secondary electron SEM image (left) and corresponding X-ray spectrum (right) illustrating spherical particles of a Cl-rich phase in the outer layer of the deposit and (b) secondary electron SEM image (left) and corresponding X-ray spectrum (right) illustrating crystals of Fe-rich oxide in the inner layer of the deposit near the metal surface.
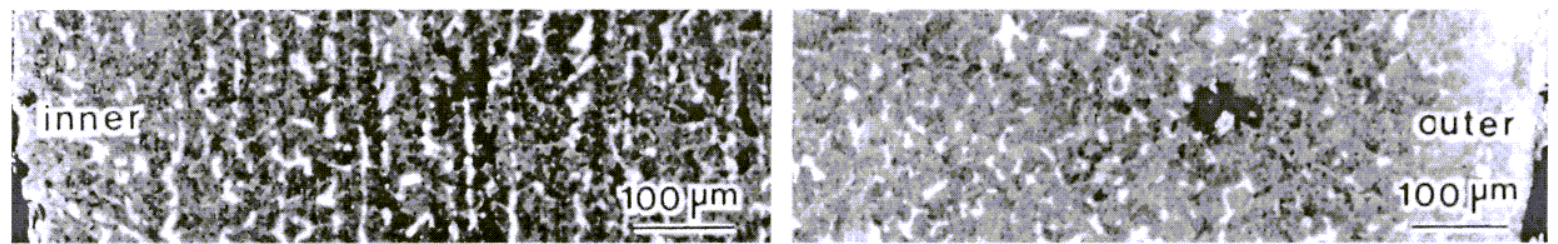

Fig. 5. Secondary electron SEM images illustrating gross microstructural features of the $16 \mathrm{in.}$ header along the transverse direction. Pipe showing elongated pearlite near the inner surface (left).

high. This attack can occur in any pearlitic steel irrespective of its composition, and primarily depends on the amount of hydroxide, level of stress and effectiveness of corrosion inhibitors [1]. In the present study all three factors namely, the accumulation of chlorine, high stresses due to cold working and an absence of corrosion inhibitor, were observed and thought to have contributed in the corrosion attack.

Surface scale formed on the $10 \mathrm{in}$. header consisted essentially of iron-rich oxides as illustrated in Fig. 9. In contrast to the 16 in. header, there was no evidence for the formation of chlorine-rich phases.

\subsection{Corrosion properties of carbon steels}

Generally, the majority of impurity constituents in plain carbon steels have no effect on their corrosion resistance in aerated neutral and caustic environments [2,3]. In such neutral environments, corrosion is controlled by diffusion of oxygen through a partially protective $\mathrm{Fe}(\mathrm{OH})_{2}$ film which is reduced on the alloy surface. Accordingly, corrosion rates are controlled by the availability of oxygen and in turn the environment rather than the alloy composition.

A behavior different from that described above is known to occur in the presence of $\mathrm{NaCl}$ solution. In this case, the corrosion rate is considerably increased when the $C$ content is varied from $0.1 \%$ to $0.8 \%$ [3]. As demonstrated earlier, however, there appeared to be no significant difference in the $\mathrm{C}$ contents of the pipe and flange materials.

Carbon steels are also known to corrode rapidly in acidic environments such as hydrochloric, phosphoric or nitric acids as well as in chlorine-contaminated environments [2]. Reference to the caustic cell reaction described earlier suggests the pos- 

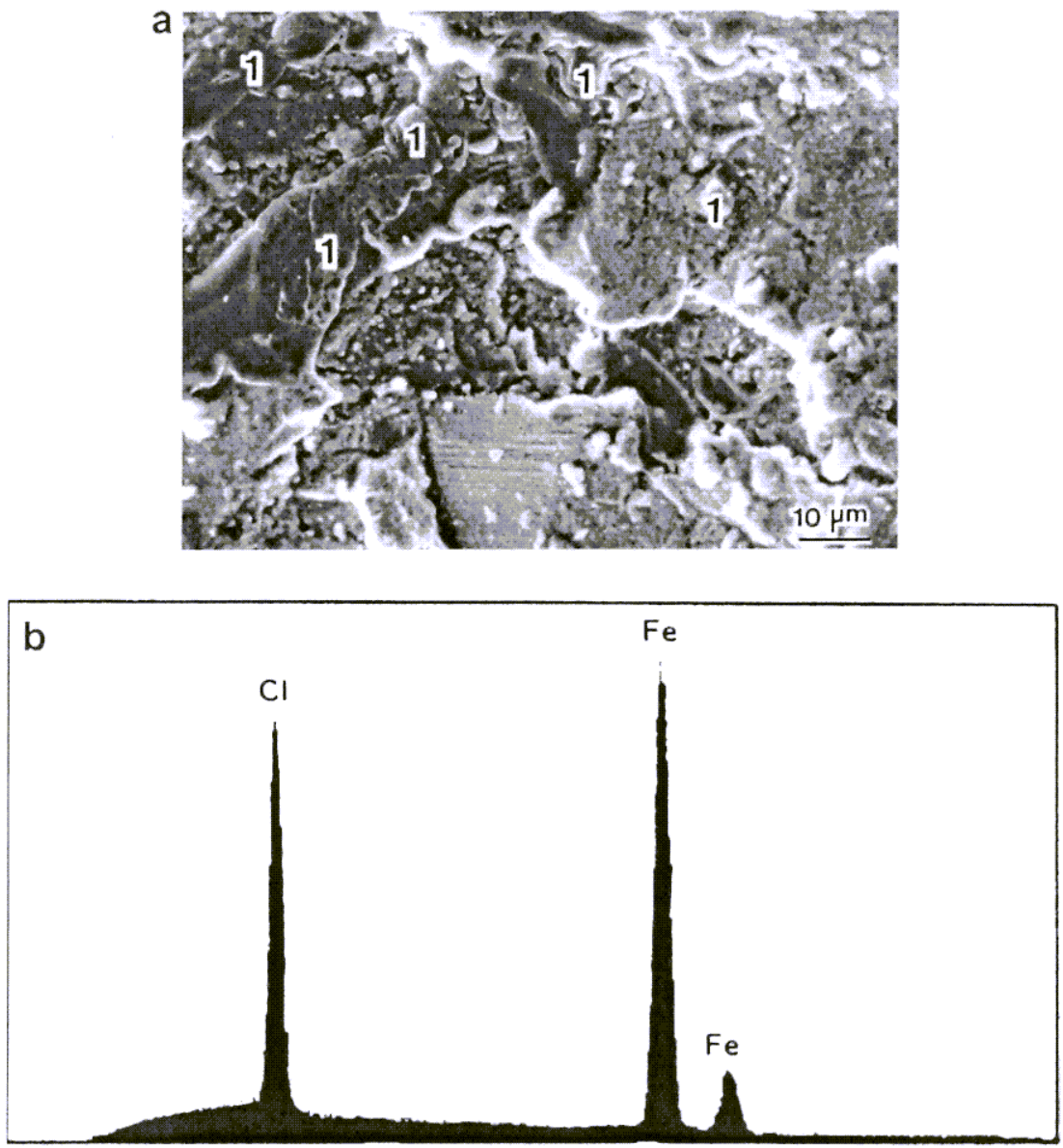

Fig. 6. Identification of iron chloride in the surface scale formed on the $16 \mathrm{in.}$ header at the top section: (a) secondary electron SEM image illustrating the morphology of scale formed on the inner surface of the pipe and (b) energy dispersive X-ray spectrum representative of the regions marked (1) in (a).

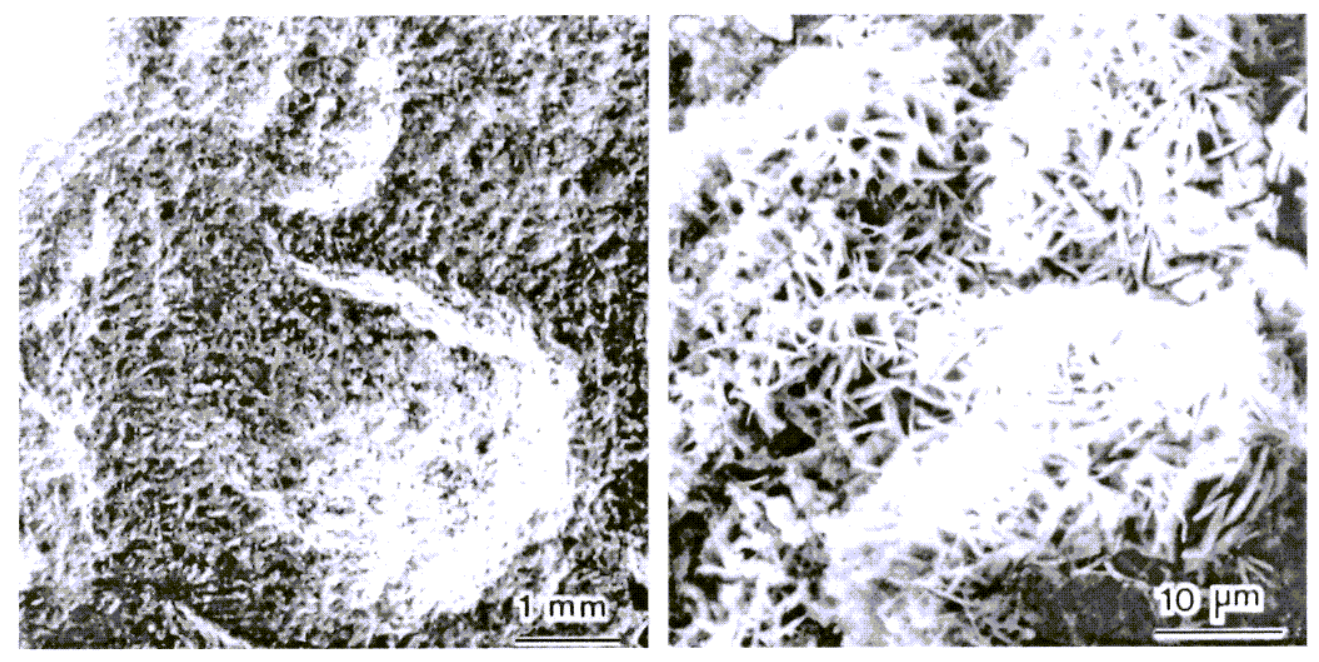

Fig. 7. Secondary electron SEM images illustrating the morphology of surface pits at the inner section of the 16 in. header as observed at different magnifications (flange at the bottom section). Iron oxide crystals are observed in the image to the right.

sibility of a corrosion attack by either chlorine and/or condensed hydrochloric acid. An evidence for this suggestion was provided by the detection of iron chlorides in the corrosion deposit. 

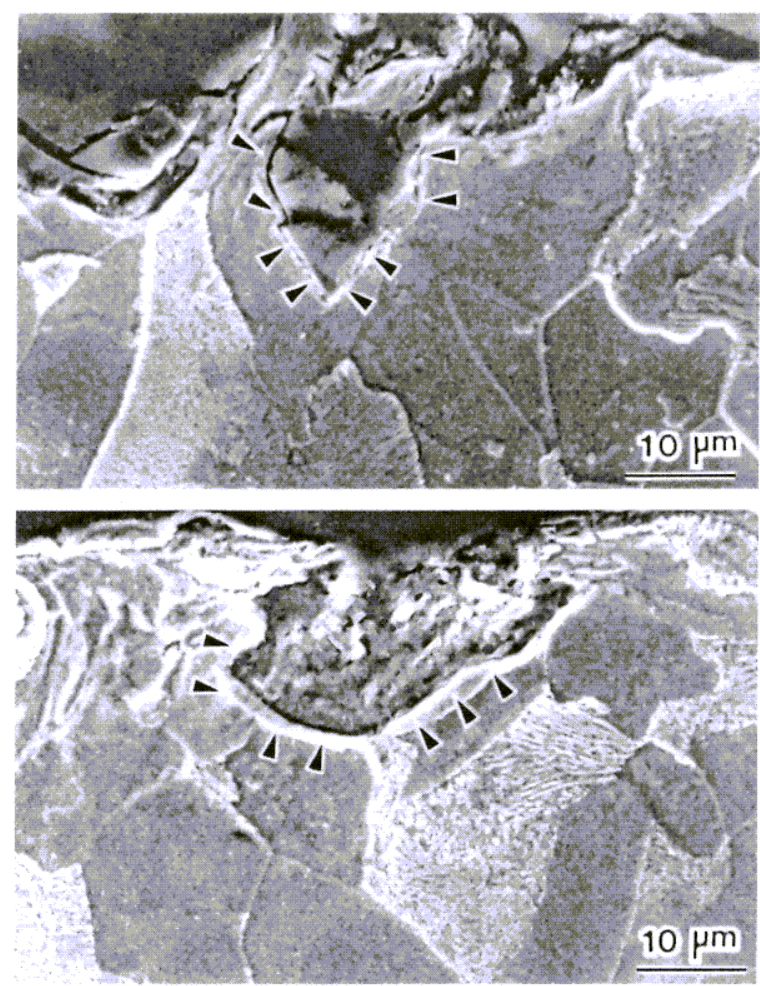

Fig. 8. Secondary electron SEM images illustrating the morphology of surface pits along the transverse direction of the 16 in. header (flange at the bottom section). Intergranular crack is indicated by arrows.

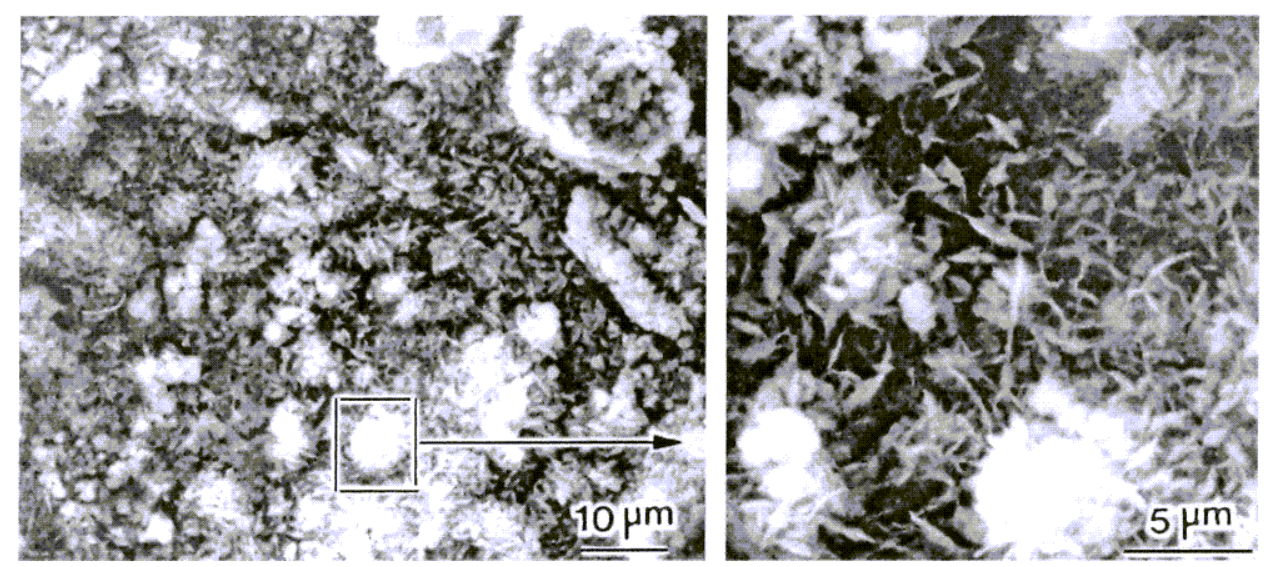

Fig. 9. Secondary electron SEM images illustrating the morphology of iron oxide crystals formed at the inner surface of the 10 in. header (pipe): same region observed at different magnifications.

Although carbon steels may provide satisfactory performance in caustic environments, Ni-base alloys particularly those containing Mo are considered more reliable in terms of long-term performance [2].

\section{Mode of failure}

Based upon the results of this study, the mode of failure of the $16 \mathrm{in}$. header appeared to be localized attack by chlorine and/or hydrochloric acid resulting from accumulation of concentrated solutions at pipe connections (flanges).

\section{Probable cause of failure}

Depending upon the caustic concentration and operating temperature, carbon steels are recommended for applications such as the one investigated here [1]. However, a reference to the standard caustic soda service graph [4] indicates that 
the operating conditions listed in Table 1 renders the piping system close to a critical transition range. Due to this fact, carbon steel does not appear to be a suitable choice of material at an operating temperature of $110^{\circ} \mathrm{C}$. However, most evidence pointed out that there could be more than one cause for the observed failure. First, condensation of $\mathrm{HCl}$ could result in the failure since carbon steels have poor corrosion resistance to this acid. Secondly, use of piping system within critical operating conditions would result in the materials-related failure observed here. Thirdly, misalignment of the pipe at the flange leading to a cold worked layer at the surface could accelerate the corrosion attack particularly in the absence or insufficiency of inhibitors [1].

\section{Conclusions}

It could be concluded from this study that that the mode of failure of the 16 in. header was severe corrosion attack by chlorine and/or hydrochloric acid since the piping system was being used close to critical operating conditions. Possibly, misalignment of the pipe at the flange and the associated cold work led to an accelerated corrosion rate.

\section{Recommendations}

It was recommended to consider proper alignment of the pipe and avoidance of cold work as well as the addition of inhibitors. However, for a long-term solution, it was recommended to consider replacing the header material by one of the higher grade $\mathrm{Ni}$-base alloys such as the $\mathrm{Ni}-\mathrm{Cr}-\mathrm{Mo}$ HASTELLOY alloy C-276.

\section{Acknowledgements}

The authors wish to acknowledge the support provided by the Research Institute at King Fahd University of Petroleum and Minerals, Dhahran, Saudi Arabia.

\section{References}

[1] Metals handbook. Properties and selection of materials, vol. 1. 8th ed. Ohio: ASM Metals Park; 1977. p. 276.

[2] Schweitzer PA, editor. Carbon steel and low alloy steel in corrosion and corrosion protection handbook. New York: Marcel Dekker; 1983.

[3] Duquette DJ. Aqueous and stress corrosion resistance. In: Tien JK, Ansell GS, editors. Alloy and microstructural design. New York: Academic Press; 1976. p. 251.

[4] Caustic soda service graph. NACE corrosion data survey. 5th ed:; 1971. 